\title{
Cryopreservation of Indonesian native chicken semen by using dimethyl sulfoxide and various level of ethylene glycol as cryoprotectants
}

\author{
KHAERUDDIN $^{1, \boldsymbol{v}}$, JUNAEDI ${ }^{2}$, HASTUTI ${ }^{2}$ \\ ${ }^{1}$ Program of Animal Science, Faculty of Science and Technology, Universitas Muhammadiyah Sinjai. J1. Teuku Umar No. 8, Sinjai 92611, South \\ Sulawesi, Indonesia. Tel. +62-482-22954, ^email: erukhaeruddin@ gmail.com \\ ${ }^{2}$ Department of Animal Husbandry, Faculty of Agriculture, Fisheries and Animal Husbandry, Universitas Sembilanbelas November. \\ J1. Pemuda No. 339, Kolaka 93517, Southeast Sulawesi, Indonesia
}

Manuscript received: 23 September 2020. Revision accepted: 23 November 2020

\begin{abstract}
Khaeruddin, Junaedi, Hastuti. 2020. Cryopreservation of Indonesian native chicken semen by using dimethyl sulfoxide and various level of ethylene glycol as cryoprotectants. Biodiversitas 21: 5718-5722. Imported purebred chickens are becoming more popular and a regular staple in Indonesia. Therefore, it is necessary to strengthen conservation efforts to preserve Indonesian chickens, one of which is by means of sperm cryopreservation. This study aimed to determine the effects of the addition of DMSO and different concentrations of ethylene glycol to a Ringer's lactate egg yolk (RLY)-or coconut water egg yolk (CWY)-based extender on the quality of frozen-thawed Indonesian chicken sperm. This study was used nine Indonesian native roosters about 20 months of age. The semen extenders used in this study were RLY + DMSO 7\%, RLY + ethylene glycol 3\%, RLY + ethylene glycol 5\%, RLY + ethylene glycol $7 \%, \mathrm{CWY}+\mathrm{DMSO} 7 \%, \mathrm{CWY}+$ ethylene glycol 3\%, CWY + ethylene glycol 5\% and CWY + ethylene glycol 7\%. Liquid semen was packaged in $0.25 \mathrm{~mL}$ straw, then cooled at $5^{\circ} \mathrm{C}$ for 2 hours, frozen at $5 \mathrm{~cm}$ above liquid nitrogen for 10 minutes, following stored in a liquid nitrogen container for 24 hours. The semen straws were thawed at $37^{\circ} \mathrm{C}$ for 30 seconds. Statistical analysis for multiple comparisons was performed as a completely randomized design with eight treatment levels and seven replications. The results showed that there were no differences in sperm motility, recovery rate, and abnormality between extenders after the freeze-thaw process. Whereas, RLY + DMSO 7\% was the highest sperm viability.
\end{abstract}

Keywords: Cryopreservation, DMSO, ethylene glycol, Indonesian chicken sperm

\section{INTRODUCTION}

Indonesia has different types of chickens (Gallus gallus domesticus) that can be found across several islands. However, imported purebred chickens are becoming more popular and a regular staple in Indonesia. It is, therefore, necessary to strengthen conservation efforts to preserve Indonesian chickens. Cryopreservation is one of the effective methods of preserving chicken sperm. According to Bhattacharya and Prajapati (2016), the main objective of cryopreservation is to create a dehydrating environment for preserving cells. One factor that can determine the success of cryopreservation is the composition of the semen extender, as it affects the quality of the sperm after the freeze-thaw process. Coconut water is an inexpensive extender and contains essential nutrients, namely sugar and several minerals, needed by chicken sperm during storage. Ringer's lactate has been proven to be a good semen extender due to its isotonic properties and has been widely studied in Indonesian chicken semen stored at $5^{\circ} \mathrm{C}$.

Penetrative cryoprotectants are among the ingredients added to extenders to protect sperm from the harmful effects of freezing. According to Bhattacharya and Prajapati (2016), penetrative cryoprotectants have a molecular mass of fewer than $100 \mathrm{kDa}$ and penetrate inside the cells and maintain moisture during freeze-drying. Glycerol, dimethylacetamide, and dimethyl sulfoxide (DMSO) were cryoprotectants that had been reported in the freezing of Indonesian native chicken sperm (Junaedi et al. 2016a,b, 2017, 2019). DMSO is an organosulfur derivative. Its molecular formula is $\left(\mathrm{CH}_{3}\right) 2 \mathrm{SO}$. This colorless solution can be able to dissolve both polar and non-polar compounds (Bhattacharya and Prajapati 2016). Another cryoprotectant that could potentially be used in chicken sperm cryodiluent is ethylene glycol (EG). Ethylene glycol has a molecular weight of $62.1 \mathrm{~g} \mathrm{~mol}^{-1}$, lower than the molecular weight of DMSO, which is $78.3 \mathrm{~g} \mathrm{~mol}^{-1}$ (Leibo and Pool 2011). According to Bhattacharya and Prajapati (2016), ethylene glycol alters the hydrogen bonding when it mixes with water. After mixing with $40 \%$ water and $60 \%$ ethylene glycol, the freezing point of the mixture would depress and the mixture becomes incapable of forming crystalline substances. This property of ethylene glycol makes it the most effective candidate for cryoprotection.

Previous studies have proven the effectiveness of ethylene glycol in mammalian sperm freezing. Silva et al. (2012) found that the progressive motility of sheep sperm after thawing was higher at 3-5\% ethylene glycol when compared to acetamide. Meanwhile, Chen et al. (2017) stated that Ethylene glycol had the same ability as glycerol in maintaining motility, acrosome integrity, and mitochondrial membrane potential in apes' sperm.

The use of ethylene glycol resulted in higher motility of the dog's sperm after thawing compared to glycerol (Rota et al. 2006). Other reports indicate that the increase of sperm quality and pregnancy rate in buffaloes occurred 
when glycerol was replaced by ethylene glycol in an extender containing egg yolk (Swelum et al. 2011). Ethylene glycol has been reported to be used in cryodiluent of muscovy duck sperm, but it is not as good as the use of DMSO (Gerzilov 2010). However, DMSO and ethylene glycol are suitable for cryopreservation of semen of Venda chickens (Mphaphathi et al. 2016). However, the concentration of cryoprotectant needs to be investigated. According to Bhattacharya and Prajapati (2016), the optimization of cryoprotectants as elevated concentration could cause cytotoxicity. This study aimed to determine the effects of the addition of DMSO and different concentrations of ethylene glycol to a Ringer's lactate egg yolk-or coconut water egg yolk-based extender on the quality of frozen-thawed Indonesian chicken sperm.

\section{MATERIALS AND METHODS}

\section{Collection and evaluation of the semen}

This study was used nine Indonesian native roosters about 20 months of age. The chickens were kept in individual cages measuring $40 \times 50 \times 70 \mathrm{~cm}^{3}$ and given a total of 150 grams of chicken feed daily and drinking water was given by ad libitum. Semen was collected in the morning at 07.30 using a massage technique based on Burrows and Quinn (1936). Semen was obtained by placing the left hand on the back of the chicken and massaging around the cloaca with two fingers until the papilla protruded. This protrusion of the papilla was followed by the ejaculation of fresh semen. The semen that was collected was immediately evaluated for characteristics both macroscopically (volume, color, viscosity, and $\mathrm{pH}$ ) and microscopic (sperm concentration, sperm mass movement, sperm motility, sperm viability, and sperm abnormality).

Sperm concentration was calculated using a hemocytometer Neubauer chamber under a 160x magnification microscope, and mass movement was evaluated by observing a drop of semen on a glass slide and evaluated under a binocular light microscope (Boeco, Germany) with $160 x$ magnification microscope. The motility of the sperm was determined by viewing some semen on a glass slide with a cover glass under a 400x magnification microscope. To determine the viability and abnormality of the sperm, some semen was stained with eosin-nigrosin (Merck, KgaA, Darmstadt Germany) on a glass slide, homogenized, placed on a glass slide, and dried on a heating table for 5 seconds. Ten fields of view were determined under a 640x magnification microscope by calculating the percentage of sperm that did not absorb eosin-nigrosin (viability) and the percentage of abnormal morphology (abnormality). The entire procedure for evaluating the quality of the sperm was carried out according to Arifiantini (2012).

\section{Extender preparation}

The basic extender was made from Ringer's lactate (PT. Widatra Bakti, Indonesia) which contained $1.55 \mathrm{~g}$ of sodium lactate, $3 \mathrm{~g}$ of sodium chloride, $0.15 \mathrm{~g}$ potassium chloride, and $0.1 \mathrm{~g}$ of calcium chloride in $500 \mathrm{~mL}$ sterile water, with osmolarity $274 \mathrm{mOsm} \mathrm{L}^{-1}$, or natural young coconut water which was $\mathrm{pH}$ adjusted. Ringer's lactate egg yolk (RLY) and coconut water egg yolk (CWY) were added with $9 \%$ chicken egg yolk and then centrifuged at $2000 \mathrm{rpm}$ for 20. The supernatant was used as a basic extender with penicillin $1000 \mathrm{IU} \mathrm{mL} \mathrm{m}^{-1}$ (PT. Meiji, Indonesia), $1 \mathrm{mg} \mathrm{mL}^{-1}$ streptomycin (PT. Meiji, Indonesia) and $80 \mathrm{mM}$ glucose (Merck, KgaA, Darmstadt Germany) were stirred for 5 minutes. The extender was adjusted to a $\mathrm{pH}$ of 6.5 using tris (hydroxymethyl) aminomethane (Merck, KgaA, Darmstadt Germany). Eight tubes were filled with different extenders. The first tube was filled with RLY + DMSO 7\% (Merck, KgaA, Darmstadt Germany), the second tube was filled with CWY + DMSO $7 \%$, the third tube was filled with RLY + EG 3\% (Merck, KgaA, Darmstadt Germany), the fourth tube was filled with RLY + EG 5\%, the fifth tube was filled with RLY + EG $7 \%$, the sixth tube was filled with CWY + EG 3\%, the seventh tube was filled with CWY + EG 5\%, and the eighth tube was filled with CWY + EG 7\%.

\section{Dilution, freezing, and thawing}

The minimum concentration of sperm used in the subsequent freezing process was $2400 \times 10^{6} \mathrm{~mL}^{-1}$, and sperm motility was at least $80 \%$. For the freezing process, the semen was divided into eight equal parts and placed into the tubes containing the extenders. The semen was divided into eight parts containing extenders RLY + DMSO 7\%, CWY + DMSO 7\%, RLY + EG 3\%, RLY + $\mathrm{EG} 5 \%, \mathrm{RLY}+\mathrm{EG} 7 \%, \mathrm{CWY}+\mathrm{EG} 3 \%, \mathrm{CWY}+\mathrm{EG} 5 \%$ and $\mathrm{CWY}+\mathrm{EG} 7 \%$, where the ratio of extenders to semen was 10: 1. Diluted semen was packaged in $0.25 \mathrm{~mL}$ straws (IMV, France). Each straw had a minimum sperm concentration of $60 \times 10^{6} \mathrm{~mL}^{-1}$.

The straws were cooled to $5{ }^{\circ} \mathrm{C}$ for 2 hours for equilibration. The semen straws were frozen at $5 \mathrm{~cm}$ above liquid nitrogen for 10 minutes (Bearden et al. 2004) and stored in a liquid nitrogen container for 24 hours. The semen straws were thawed at $37^{\circ} \mathrm{C}$ for 30 seconds using a water bath (Shah et al. 2016), and then the sperm was evaluated. The recovery rate of motility was calculated by dividing the post-thaw motility by the sperm motility of fresh semen and presented as a percentage.

\section{Statistical analysis}

Statistical analysis for multiple comparisons was performed using a completely randomized design with eight treatment levels and seven replications. Motility, viability, and abnormality after dilution and after freezingthawing and recovery rate were analyzed using ANOVA, if the F-value is significant $(\mathrm{P}<0.05)$ then it was followed by Duncan multiple range test. Statistical analysis used SPSS 16 applications on Windows. 


\section{RESULTS AND DISCUSSION}

\section{Characteristics of fresh semen}

The raw-semen characteristics of Indonesian native chicken were presented in Table 1 . The average volume was $0.24 \mathrm{~mL}$, thick consistency, milky white color, and a $\mathrm{pH}$ of 6.45 . The average sperm mass activity was +++ which described thick and fast-moving sperm mass waves, sperm concentration of $4054.17 \times 10^{6} \mathrm{~mL}^{-1}$, sperm motility of $90 \%$, sperm viability of $97.07 \%$, and sperm abnormality of $7.73 \%$. The characteristics of the semen had the standards to proceed to the freezing stage.

\section{Sperm quality after dilution}

The result showed that there was no significant difference $(\mathrm{P}>0.05)$ in the motility and viability of sperm between treatments (Table 2). Sperm motility and viability were within the ranges of $87-88.43 \%$ and $96.55-98.25 \%$, respectively. There was a significant $(\mathrm{P}<0.05)$ difference in sperm abnormality. The use of $7 \%$ DMSO resulted in a higher abnormality (8.24-8.67\%) than the use of ethylene glycol (3.80-4.40\%). However, no difference in abnormality was observed between 7\% DMSO and ethylene glycol in coconut water egg yolk extender $(5.88$ $6.34 \%)$.

\section{Spermatozoa quality after thawing}

The results from the sperm motility, abnormality, and recovery rate showed that there was no significant difference $(\mathrm{P}>0.05)$ between the treatments (Table 3). Sperm motility was in the range of $24.28-32 \%$, the abnormality was $6.74-9.05 \%$, and the recovery rate was 27.1-35.74\%. Sperm viability showed a difference (P $<0.01)$ between treatments. The highest sperm viability was observed in the batch containing Ringer's lactate egg yolk extender with $7 \%$ DMSO $(44.62 \%)$, while the other treatment showed low viability $(24.64-33.78 \%)$.

Table 1. The average of fresh semen characteristics of Indonesia native chicken

\begin{tabular}{ll}
\hline Parameter & Mean \pm SEM \\
\hline Volume $(\mathrm{mL})$ & $0.24 \pm 0.03$ \\
Color & Milk white \\
Consistency & Thick \\
$\mathrm{pH}$ & $6.45 \pm 0.10$ \\
Spermatozoa concentration $\left(\mathrm{x} 10^{6} / \mathrm{mL}\right)$ & $4054.17 \pm 610.2$ \\
Movement of spermatozoa mass & +++ \\
Spermatozoa motility $(\%)$ & $90.00 \pm 1.75$ \\
Spermatozoa viability $(\%)$ & $97.07 \pm 0.42$ \\
Spermatozoa abnormalities $(\%)$ & $7.73 \pm 1.08$ \\
\hline
\end{tabular}

Table 2. Quality of Indonesian native chicken spermatozoa after dilution with LRY and CWY added with dimethyl sulfoxide and various levels of ethylene glycol

\begin{tabular}{lccc}
\hline \multirow{2}{*}{ Treatment } & \multicolumn{3}{c}{ Variable of spermatozoa (\%) (mean \pm SEM) } \\
\cline { 2 - 4 } & Motility & Viability & Abnormality \\
\hline LRY + DMSO 7\% & $88.28 \pm 0.61$ & $96.76 \pm 0.50$ & $8.67 \pm 1.21 \mathrm{a}$ \\
CWY + DMSO 7\% & $87.57 \pm 0.68$ & $97.67 \pm 0.33$ & $8.24 \pm 1.04 \mathrm{a}$ \\
LRY + EG 3\% & $88.28 \pm 0.61$ & $97.13 \pm 0.55$ & $3.80 \pm 0.90 \mathrm{~b}$ \\
LRY + EG 5\% & $88.00 \pm 0.75$ & $97.09 \pm 0.85$ & $4.40 \pm 0.76 \mathrm{~b}$ \\
LRY + EG 7\% & $88.43 \pm 0.78$ & $96.82 \pm 0.55$ & $4.18 \pm 0.73 \mathrm{~b}$ \\
CWY + EG 3\% & $87.14 \pm 0.55$ & $98.25 \pm 0.19$ & $6.34 \pm 0.46 \mathrm{ab}$ \\
CWY + EG 5\% & $87.43 \pm 0.43$ & $97.46 \pm 0.70$ & $5.88 \pm 1.54 \mathrm{ab}$ \\
CWY + EG 7\% & $87.00 \pm 0.95$ & $96.55 \pm 0.84$ & $6.00 \pm 1.36 \mathrm{ab}$ \\
\hline
\end{tabular}

Note: Different superscripts in the same column show significant differences $(\mathrm{P}<0.05)$

Table 3. Quality of Indonesian native chicken spermatozoa after thawing with LRY and CWY added with dimethyl sulfoxide and various levels of ethylene glycol

\begin{tabular}{|c|c|c|c|c|}
\hline \multirow[t]{2}{*}{ Treatments } & \multicolumn{4}{|c|}{ Variable of spermatozoa $(\%)($ mean \pm SEM $)$} \\
\hline & Motility & Viability & Abnormality & Recovery rate \\
\hline LRY + DMSO 7\% & $32.00 \pm 1.76$ & $44.62 \pm 2.40^{\mathrm{a}}$ & $8.91 \pm 0.83$ & $35.74 \pm 2.00$ \\
\hline CWY + DMSO 7\% & $31.14 \pm 1.33$ & $33.78 \pm 3.16^{\mathrm{b}}$ & $8.83 \pm 1.98$ & $34.79 \pm 1.54$ \\
\hline $\mathrm{LRY}+\mathrm{EG} 3 \%$ & $27.71 \pm 1.95$ & $28.92 \pm 3.81^{b}$ & $8.41 \pm 1.42$ & $30.93 \pm 2.13$ \\
\hline LRY + EG 5\% & $26.86 \pm 1.74$ & $26.96 \pm 3.37^{b}$ & $9.05 \pm 1.24$ & $29.98 \pm 1.91$ \\
\hline $\mathrm{LRY}+\mathrm{EG} 7 \%$ & $27.28 \pm 1.91$ & $29.85 \pm 2.69^{b}$ & $7.40 \pm 0.78$ & $30.46 \pm 2.09$ \\
\hline $\mathrm{CWY}+\mathrm{EG} 3 \%$ & $27.28 \pm 2.10$ & $29.14 \pm 3.88^{b}$ & $7.06 \pm 1.21$ & $30.51 \pm 2.42$ \\
\hline $\mathrm{CWY}+\mathrm{EG} 5 \%$ & $26.14 \pm 1.66$ & $30.44 \pm 3.08^{\mathrm{b}}$ & $6.74 \pm 1.11$ & $29.22 \pm 1.93$ \\
\hline $\mathrm{CWY}+\mathrm{EG} 7 \%$ & $24.28 \pm 1.30$ & $24.64 \pm 2.44^{\mathrm{b}}$ & $6.83 \pm 1.12$ & $27.10 \pm 1.41$ \\
\hline
\end{tabular}

Note: Different superscripts in the same column showed a very significant effect $(\mathrm{P}<0.01)$ 


\section{Discussion}

The use of DMSO cryoprotectants and EG did not result in differences in motility after thawing, suggesting that both cryoprotectants have the same ability to maintain motility after thawing. This is consistent with the report of Mphaphathi et al. (2016) thatno difference was found in total spermatozoa motility of Venda chickens with the use of DMSO and ethylene glycol for 1 hour and 2 hours of storage. The report also explained no differences in total motility, progressive motility, non-progressive motility, and sperm velocity traits following freezing-thawing of Venda cock semen supplemented with $8 \%$ DMSO and $8 \%$ ethylene glycol. However, the post-thaw sperm motility observed in this study was lower than the previous study that post-thawing chicken spermatozoa motility in Kobidil extender supplemented with DMSO was $46 \%$ and ethylene glycol 45\% (Mphaphathi et al. 2016). This may be due to differences in the type of basic extender and the breed of chicken used.

The difference in sperm quality was determined through the viability of sperm after thawing. Ringer's lactate egg yolk extender containing DMSO maintained post-thaw spermatozoa viability better than extenders containing EG. This may be due to the low toxicity of DMSO, which resulted in higher sperm viability after the freeze-thaw process when compared to the low viability of sperm in extenders containing EG, which has higher toxicity levels. According to Bhattacharya (2018), ethylene glycol is metabolized into toxic elements when in warm conditions. Ethylene glycol has a high penetrating ability into the cell, which may cause damage to the cell membrane (Seshoka et al. 2016). Awad (2011) states that ethylene glycol has a lower molecular weight and a greater membrane permeability than DMSO. It is suspected that ethylene glycol permeates the sperm plasma membrane faster than DMSO, hence causing damage to the sperm during equilibration and cryopreservation (Gillmore et al. 2000). Sexton (1973) reported that ethylene glycol suppressed the respiration of chicken spermatozoa.

DMSO is low molecular weight and toxicity when used at low temperatures (Lake dan Ravie 1984). This is supported by Bhattacharya (2018) explaining that DMSO has low cost and minor cytotoxicity, which makes it a more prominent candidate for cryopreservation. The most important step in freezing spermatozoa cells is removing water from the cell before intracellular freezing occurs. If this dehydration does not occur, large ice crystals will form in the cells, leading to cell damage. Conversely, if there is extreme dehydration, the cells will experience dryness and die as a result. As stated by Chaytor et al. (2012), cryopreservation of cells using slow-freezing results in dehydration of the cell in response to increased osmotic pressure as electrolytes are concentrated outside the cell during extracellular ice growth.

Excessive dehydration can be prevented using cryoprotectants. Cell-penetrating cryoprotectants, such as DMSO, readily cross the cell membrane and decrease the concentration of intracellular electrolytes while maintaining greater cell volumes (Chaytor et al. 2012). Bui et al. (2013) explained that DMSO freely permeates cell membranes due to its low hydrophilicity and molecular weight and is therefore thought to disrupt ice crystal nucleation and formation by forming hydrogen bonds with water. DMSO is a polar aprotic solvent that can dissolve polar and nonpolar compounds and can be easily miscible with a wide range of organic solvents and with water (Bhattacharya 2018). Cryoprotectants, simply by increasing the total concentration of all solutes in the system, reduce the amount of ice formed at any given temperature (Pegg 2015).

The results of this viability study are consistent with the report by Gerzilov (2010) that the mobility of post-thawing muscovy spermatozoa was lower by using ethylene glycol at $3 \%, 5 \%$, and $7 \%$ when compared to use $7 \%$ DMSO. Sexton (1973) reported that sperm motility in $4 \%$ ethylene glycol was a reduction when compared to $4 \%$ glycerol or DMSO. Woelders et al. (2006) reported the use of EG as a cryoprotectant during chicken semen cryopreservation, where it was found to yield lower post-thaw motility and viability.

The viability of spermatozoa after thawing, if observed based on the type of based extender with the same cryoprotectant, namely DMSO, demonstrates that Ringer's lactate egg yolk extender maintains the viability of spermatozoa better than the coconut water egg yolk extender. This may be due to the presence of lactate in Ringer's solution, which is beneficial for spermatozoa. The research of Yamashiro et al. (2010) on rat spermatozoa showed that exogenous lactate in the freezing extender is a potent inducer that enhances the oxygen consumption of sperm and their motility after collection and freezingthawing. Lactate is used by sperm as an essential substrate to maintain highly regulated ATP production and dissipation. The sperm can use exogenous lactate in the cryodiluent as an essential substrate to maintain highly regulated metabolic capacity, and that this lactate acts as an energy substrate for mitochondria to the mobilization of fresh and frozen-thawed sperm.

Ringer's lactate contains physiologic concentrations of sodium, chloride, potassium, calcium, and lactate (Albert et al. 2009). Ringer's lactate solution has potassium and calcium at concentrations that are similar to the ionizeds concentrations found in normal blood plasma (das Neves et al. 2019; Martini et al. 2013). According to Fujita et al. (2020), the ions in Ringer's solutions prevent cell death, and in maintaining cell viability. Rashid and Qistina (2015) reported the same as this study that Ringer's extender was the best compared with coconut water evaluated in both percentages of live sperm and abnormality of kampung cockerel throughout the 6-hour storage.

Sperm abnormality shortly after dilution was lower in the Ringer's lactate egg yolk extender containing EG compared to the extenders containing DMSO. According to Alcay et al. (2016), ethylene glycol successfully protected acrosomal and DNA integrities of ram spermatozoa. The sperm abnormality found in this study was quite low after dilution, and although there was a slight increase in abnormality after thawing, it remained below $10 \%$. Bent head, midpiece, and tail were the main morphological abnormalities found in this study. According to Feyisa et 
al. (2018), there was a difference in the proportion of spermatozoa with defective segments among breeds. The results of research by Ameen et al. (2014) stated that sperm abnormalities in the Hubbard and Isa White strains were dominated by head abnormalities. Most Korean native chicken sperm abnormalities were found to occur at the tail followed by the head (Feyisa et al. 2018Viable abnormal sperm and defective tail were associated with poor motility, a high proportion of defective tail in an ejaculate volume will decrease motility, fertility, and hatchability as these defects might (Feysia et al. 2018).

In conclusion, dimethyl sulfoxide $7 \%$ was better than ethylene glycol 3\%, 5\%, and $7 \%$ in maintaining the quality of Indonesian native chicken frozen-thawed semen While Ringer's lactate extender was better than coconut water when dimethyl sulfoxide added.

\section{REFERENCES}

Albert K, van Vlymen J, James P, Parlow J. 2009. Ringer's lactate is compatible with the rapid infusion of AS-3 preserved packed red blood cells. J Can Anesth 56: 352-356. DOI: 10.1007/s12630-0099070-5.

Alcay S, Ustuner B, Nur Z. 2016. Effect of low molecular weight cryoprotectants on the post-thaw ram sperm quality and fertilizing ability. Small Ruminant Res 136: 59-64. DOI: 10.1016/j.smallrumres.2016.01.009

Ameen SA, Opayemi OS, Ajayi JA, Adediwura MA. 2014. Evaluation of semen quality of five different cockerel breed used in poultry industry in Nigeria. J Environ Issues Agric Dev Countr 6 (1): 30-36.

Arifiantini RI. 2012. Teknik Koleksi dan Evaluasi Semen pada Hewan. IPB Press, Bogor.

Awad MM. 2011. Effect of some permeating cryoprotectants on CASA motility results in cryopreserved bull spermatozoa. Anim Reprod Sci 123: 157-162. DOI: 10.1016/j.anireprosci.2011.01.003.

Bearden HJ, Fuquay JW, Willard ST. 2004. Applied Animal Reproduction. 6th ed. Pearson Prentice Hall, New Jersey.

Bhattacharya S. 2018. Cryoprotectants and their usage in cryopreservation process. In: Bozkurt Y (ed.). Cryopreservation Biotechnology in Biomedical and Biological Sciences. Intechopen, United Kingdom. DOI: 10.5772/intechopen.73413

Bhattacharya S, Prajapati BG. 2016. A review on cryoprotectant and its modern implication in cryonics. Asian J Pharm 10 (3): 154-159. DOI: 10.22377/ajp.v10i3.721

Bui TVL, Ross IL, Jakob G, Hankamer B. 2013. Impact of procedural steps and cryopreservation agents in the cryopreservation of chlorophyte microalgae. Plos One 8 (11). DOI: 10.1371/journal.pone.0078668

Burrows WH, Quinn JP. 1937. The collection of spermatozoa from the domestic fowl and Turkey. Poult Sci 16 (1): 19-24. DOI $10.3382 /$ ps.0160019.

Chaytor JL, Tokarew JM, Wu LK, Leclère M, Tam RY, Capicciotti Cj, Guolla L, von Moos E, Findlay CS, Allan DS, Ben RN. 2012. Inhibiting ice recrystallization and optimization of cell viability after cryopreservation. Glycobiology 22 (1): 123-133.

das Neves CM, Romano FR, Filho SG. 2019. New ringer's lactate gel formulation on nasal comfort and humidification. Braz J Otorhinolaryngol 85 (6): 746-752. DOI: 10.1016/j.bjorl.2018.07.004

Feyisa SG, Park YH, Kim YM, Lee BR, Jung KM, Choi SB, Cho CY, Han JY. 2018. Morphological defects of sperm and their association with motility, fertility, and hatchability in four Korean native chicken breeds. Asian-Australas J Anim Sci 31 (8): 1160-1168. DOI: 10.5713/ajas.17.0626.

Fujita Y, Nishimura M, Komori NW, Wada T, Shirakawa C, Takenawa T, Sawamoto O, Doi M. 2020. A pair cell preservation solutions for therapy with human adipose tissue-derived mesenchymal stromal cells. Regen Ther 14: 95-102. DOI: 10.1016/j.reth.2019.10.004
Gerzilov P. 2010. Influence of various cryoprotectants on the sperm mobility of Muscovy semen before and after cryopreservation. J Agric Sci Techno 2 (2): 57-60.

Gillmore JA, Liu J, Woods EJ, Peter AT, Crister JK. 2000. Cryoprotective agent and temperature effects on human sperm membrane permeabilities: convergence of theoretical and empirical approaches for optimal cryopreservation methods. Hum Reprod 15: 335-343. DOI: 10.1093/humrep/15.2.335.

Junaedi, Arifiantini RI, Sumantri C, Gunawan A. 2016a. The use of dimethyl sulfoxide as cryoprotective agent for native chicken frozen semen. J Vet 17 (2): 300-308. 10.19087/jveteriner.2016.17.2.300

Junaedi, Arifiantini RI, Sumantri C, Gunawan A. 2016b. Use pf glycerol as cryoprotectants in freezing Sentul chicken semen. CJAH 1 (2): 613. DOI: $10.31327 /$ chalaza.v1i2.165

Junaedi, Arifiantini RI, Sumantri C. 2017. The quality of Kampung broiler (KB) chicken frozen semen with DMA concentrations on yolk lactate ringer diluent. CJAH 2 (2): 19-24. DOI: 10.31327/chalaza.v2i2.292

Khaeruddin, Kurniawan ME, Soman. 2019. Cryopreservation of kampung rooster semen using egg yolk diluent from four types of poultry with different concentrations. J Kedokteran Hewan 13 (3): 60-65. DOI: 10.21157/ 10.21157/j.ked.hewan.v13i3.1489260.

Lake PE, Ravie O. 1984. An exploration of cryoprotective compounds for fowl spermatozoa. Br Poul Sci 25: 145-150. DOI: 10.1080/13632758408454852.

Leibo SP, Pool TB. 2011. The principal variables of cryopreservation: solutions, temperatures, and rate changes. Fertil Steril 96 (2): 269276. DOI: 10.1016/j.fertnstert.2011.06.065.

Martini WZ, Cortez DS, Dubick MA. 2013. Comparisons of normal saline and lactated ringer's resuscitation on hemodynamics, metabolic responses, and coagulation in pigs after severe hemorrhagic shock. Scand J Trauma Resus 21: 86. DOI: 10.1186/1757-7241-21-86.

Mphaphathi ML, Seshoka MM, Luseba D, Sutherland B, Nedambale TL. 2016. The characterisation and cryopreservation of Venda chicken semen. Asian Pac J Reprod 5 (2): 132-139. DOI: 10.1016/j.apjr.2016.01.009.

Pegg DE. 2015. Principles of cryopreservation. Methods Mol Biol. 1257: 3-19. DOI: 10.1007/978-1-4939-2193-5_1.

Rashid A, Qistina MNN. 2015. Preliminary evaluation on the use of coconut water as semen diluent for local Kampung cockerel. In: Yaakub HB, Saad WZ, Akit H, Alimon AR (eds). $2^{\text {nd }}$ Asean Regional Conference on Animal Production (ARCAP) and $36^{\text {th }}$ Malaysian Society of Animal Production (MSAP) Annual Conference. MSAP, Port Dicson, Negeri Sembilan, 1-3 June 2015.

Rota A, Milani C, Cabianca G, Martini M. 2006. Comparison between glycerol and ethylene glycol for dog semen cryopreservation. $\begin{array}{llll}\text { Theriogenology } 65 & (9): & 1848-1858 . & \text { DOI: }\end{array}$ 10.1016/j.theriogenology.2005.10.015.

Seshoka MM, Mphaphathi ML, Nedambale TL. 2016. Comparison of four different permitting and combination of two best cryoprotectants on freezing Nguni sperm evaluated with the aid of computer aided sperm $\begin{array}{llll}\text { analysis. } & \text { Cryobiology } & \text { 232-238. DOI: }\end{array}$ 10.1016/j.cryobiol.2016.04.001.

Sexton TJ. 1973. Effect of various cryoprotective agents on the viability and reproductive efficiency of chicken spermatozoa. Poult Sci 52: 1353-1357.

Shah SAH, Andrabi SMH, Qureshi IZ. 2016. Effect of equilibration times, freezing, and thawing rates on post-thaw quality of buffalo (Bubalus bubalis) bull spermatozoa. Andrology 4: 972-976. DOI: 10.1111/andr.12214

Silva ECB, Cajueiro JFP, Silva SV, Vidal AH, Soares PC, Guerra MMP. 2012. In vitro evaluation of ram sperm frozen with glycerol, ethylene glycol or acetamide. Anim Reprod Sci 132 (3-4): 155-158. DOI: 10.1016/j.anireprosci.2012.05.014.

Swelum AA, Mansour HA, Elsayed AA, Amer HAA. 2011. Comparing ethylene glycol with glycerol for cryopreservation of buffalo bull semen in egg-yolk containing extenders. Theriogenology 76 (5): 833842. DOI: 10.1016/j.theriogenology.2011.04.015.

Woelders H, Zuidberg CA, Hiemstra SJ. 2006. Animal genetic resources conservation in the Netherlands and Europe: Poultry perspective. Poult Sci 85: 216-222. DOI: 10.1093/ps/85.2.216.

Yamashiro H, Toyomizu M, Kikusato M, Toyama N, Sugimura S, Hoshino Y, Abe H, Moisyadi S, Sato E. 2010. Lactate and Adenosine Triphosphate in the Extender Enhance the Cryosurvival of Rat Epididymal Sperm. J Am Assoc Lab Anim Sci 49 (2): 160-166. 